\title{
Feathers fly over welfare of hemmed-in hens
}

Laura Nelson, London

Cramming chickens together in a confined living space isn't as bad for them as one might think, according to a study published on page 342 of this issue.

The results, which reveal that temperature and air quality have a greater impact on chicken mortality than cramped conditions, are expected to be used by the poultry industry to attack proposed regulations by the European Union (EU) on chicken welfare. But defenders of the regulations maintain that controlling stocking density is the most realistic way to improve the welfare of the chickens.

Worldwide, more than 20 billion chickens are killed for human consumption every year, and the industry is facing growing criti- cism over the conditions in which most of the birds are kept.

The researchers, led by Marian Dawkins, an animal behavioural scientist at the University of Oxford, say that their study is the largest attempt so far to shed some scientific light on this emotionally charged debate. "Nobody had looked at this before," says Dawkins.

The three-year study, which was funded by the UK government, monitored 2.7 million birds reared by ten broiler-producing companies. The birds were kept at densities of between $30 \mathrm{~kg}$ per square metre - the maximum proposed in a 2000 report that is expected to form the basis of the new EU regulations - and $46 \mathrm{~kg}$ per square metre. Welfare was assessed by measuring mortality, levels of the stress hormone corticosterone

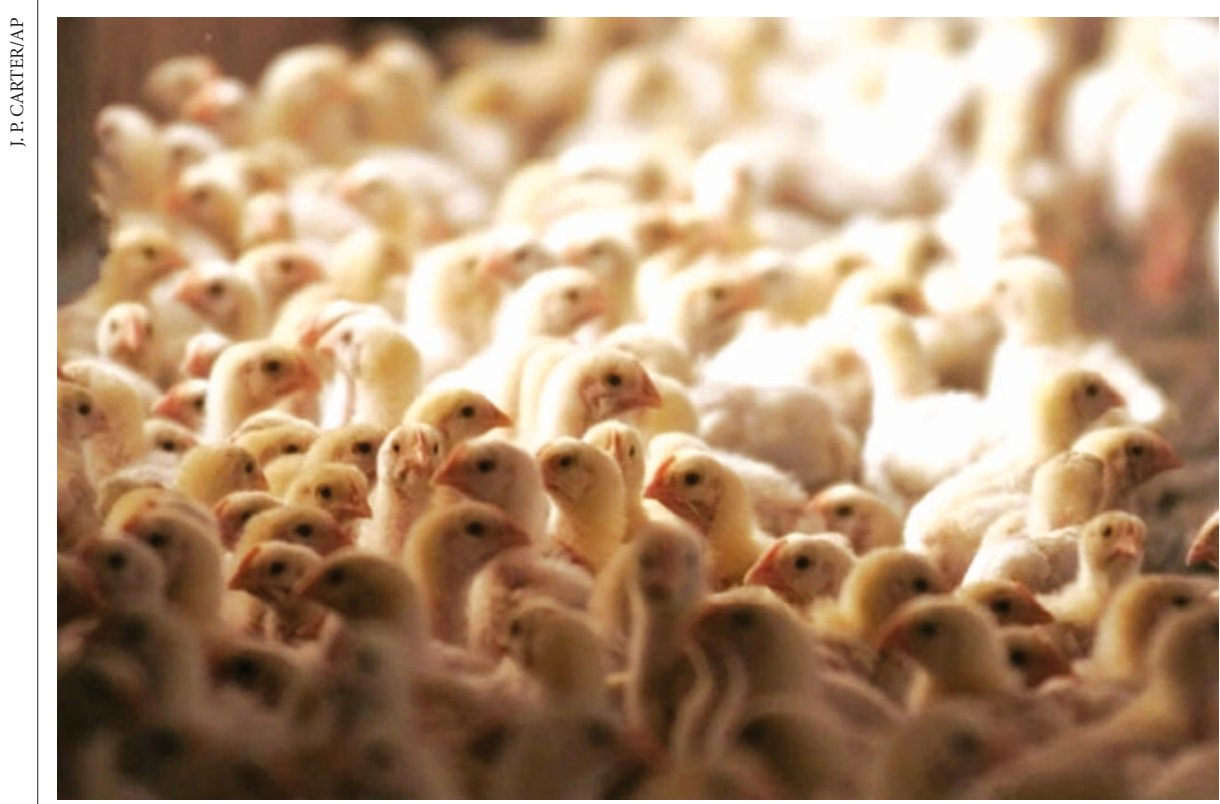

Close encounters: temperature and air quality may be the main influences on the health of chickens. in the faeces, ease of walking and the presence of skin lesions on the birds' legs and feet.

Although chickens reared in the more crowded conditions grew more slowly, the number dying, being culled as unfit, or showing leg injuries did not correlate directly with stocking density, the authors found. But mortality was directly related to humidity and temperature. Disparities between the birds held by different producers had far more effect on mortality than did stocking density.

"The results showed that although very high stocking densities do affect chicken welfare, stocking density per se is, within limits, less important than other factors in the birds' environment," says Dawkins.

But Britain's Royal Society for the Prevention of Cruelty to Animals (RSPCA) says that the study doesn't sufficiently emphasize adverse impacts other than mortality. Caroline Le Sueur, an RSPCA spokeswoman, points out that the results show that birds grown in crowded conditions are more likely to jostle one another and to walk irregularly.

The study should have dwelt more on the "quality of life" of closely confined animals, Le Sueur suggests. "We would be very concerned if industry thought it could get away with high stocking densities."

Defenders of the EU regulations, which are expected to be published later this year, point out that stocking density is easier for inspectors to monitor than factors that directly correlate with chicken mortality, such as the levels of ammonia in the air the birds breathe.

But European poultry producers say the study shows that stocking density is the wrong focus for the regulations. A spokesman for the British Poultry Council says the industry recognizes that good chicken welfare is good for business, but he adds that US producers don't have to deal with welfare rules for chickens.

\section{Ministers prepare to back neuroscience network}

\section{Declan Butler, Paris}

Brain scientists around the world wrestling with the thorny problem of how to share their data should soon find their lives getting a little easier.

Plans for an international facility to integrate such information are expected to be endorsed next week at a meeting in Paris of 30 science ministers from countries in the Organisation for Economic Co-operation and Development (OECD).

The planned International Neuroinformatics Coordinating Facility would bring together disparate neuroscience databases to allow researchers to share and compare their results more readily (see Nature 406, 822-825; 2000).

The facility would build its own databases, nurture agreements between nations on data sharing, and even fund some research on neuroinformatics, says Stefan Michalowski, executive secretary of the OECD's Global Science Forum. The annual cost of the administrative body that would run the facility would be about US\$1.2 million.

The facility would be modelled on the Copenhagen-based Global Biodiversity Information Facility, which performs a similar function with biodiversity data and was endorsed at the last OECD ministerial science meeting in Paris in 1999.

The ministers meeting in Paris are also expected to declare their support for a nextgeneration electron-positron linear collider to succeed the Large Hadron Collider, which is currently being assembled at CERN, the European particle-physics lab near Geneva. They are also likely to call on governments and research agencies to have the new collider built as a genuinely global project.

In addition, the ministers are set to draft a declaration supporting open access to data generated by publicly funded research. The resolution would ask the OECD to develop international principles and guidelines to help maximize open access, for example by making data sharing a requirement in grant proposals. 